\title{
UTILIZAÇÃO DE BORRACHA MOÍDA COMO POLÍMERO MODIFICADOR DO CAP NA PAVIMENTAÇÃO ASFÁLTICA
}

\section{ARTIGO ORIGINAL}

MARTINS, Khetulen Eduarda Santos ${ }^{1}$

DAM, Jaine Covizzi ${ }^{2}$

FERREIRA, Mônica Fernandes ${ }^{3}$

MARTINS, Khetulen Eduarda Santos. DAM, Jaine Covizzi. FERREIRA, Mônica Fernandes. Utilização de borracha moída como polímero modificador do CAP na pavimentação asfáltica. Revista Científica Multidisciplinar Núcleo do Conhecimento. Ano 05, Ed. 09, Vol. 07, pp. 60-74. Setembro de 2020. ISSN: 2448-0959, Link de acesso: https://www.nucleodoconhecimento.com.br/engenharia-civil/borracha-moida

\section{RESUMO}

O presente artigo busca apresentar em especifico o revestimento de asfalto borracha, um revestimento cujo sua utilização além de proporcionar melhorias ao pavimento, reduz os impactos ambientais gerados pelo descarte incorreto de pneus inservíveis, ou seja, quando chegados ao fim de sua vida útil, já que o mesmo contém borracha sintética em sua composição. Serão apresentados também outros tipos de revestimentos flexíveis, semirrígidos, e rígidos, utilizados na pavimentação, destacando entre eles os: Tratamentos Superficiais (TS), Pré-Misturados a Frio (PMF), Microrrevestimento Asfáltico a Frio (MRAF), Concreto Betuminoso Usinado a Quente (CBUQ), Pavimentos de Concreto (PC), e em especifico um revestimento

\footnotetext{
${ }^{1}$ Graduanda em Engenharia Civil.

2 Graduanda em Engenharia Civil.

3 Especialização em Engenharia de Segurança do Trabalho. Graduação em Engenharia Civil.
} 
modificado por polímero conhecido como Asfalto Borracha (AB), dando definições a cada um para melhor entendimento do assunto abordado. As informações contidas nesse artigo baseiam-se em revisões bibliográficas de livros da área de pavimentação, manual de pavimentação do Departamento Nacional de Infraestrutura e Transporte (DNIT), normas da Associação Brasileira de Normas Técnicas (ABNT), e Conselho Nacional do Meio Ambiente (CONAMA).

Palavras-chave: Pavimentação, DNIT, asfalto borracha.

\section{INTRODUÇÃO}

Com o decorrer dos anos, as estradas começaram a ganhar aperfeiçoamento, de forma que facilitassem o transporte de se locomover de um determinado local a outro. No final do século XVIII, foi construída a primeira estrada pavimentada no Brasil, batizada como calçada do Lorena, por ter sido seu idealizador Bernardo José de Lorena governador de São Paulo na época, a calçada do Lorena ligava o planalto paulista ao Porto de Santos. Junto com o desenvolvimento das estradas pavimentadas, está o desenvolvimento dos tipos de revestimento utilizados nas mesmas, de acordo com as necessidades de cada local a ser pavimentado.

Nesse artigo destacaremos um revestimento que traz uma solução para o descarte incorreto de pneus no meio ambiente, o asfalto borracha, também conhecido como ECOFLEX, por ser um pavimento ecológico, que visa dar uma destinação final adequada aos pneus após sua vida útil, no devido pavimento, a borracha é incorporada ao Concreto Asfáltico de Petróleo (CAP) com propósito de proporcionar melhorias ao pavimento em questão. Será abordado também sobre os principais tipos de revestimentos utilizados na pavimentação, destacando principais características, e definições de cada um, para melhor entendimento do assunto abordado.

\section{PAVIMENTAÇÃO}

Pavimentação pode ser entendida como revestimento do solo, capaz de resistir a esforços obtidos a partir do trânsito de veículos sob o mesmo. Analisando o Manual 
de Pavimentação do DNIT (2006), podemos concluir que os pavimentos são classificados em rígidos, semirrígidos, e flexíveis.

-Pavimentos rígidos: seu revestimento possui rigidez elevada em relação às demais camadas devido à absorção de grande parcela de esforços solicitantes, são compostos por uma base de concreto, apresenta maior resistência a cargas, portanto é indicado para vias cujo tráfego é mais pesado, como por exemplo: corredores de ônibus, e aeroportos (DNIT, 2006).

-Pavimentos semirrígidos: composto por base ou sub-base em material tratado com cimento de elevada rigidez, e revestimento. O pavimento semirrígido é intermediário entre pavimentos rígidos e flexíveis, apresenta deformação maior do que no pavimento rígido e menor que o flexível. O pavimento semirrígido pode ser combinado com o pavimento rígido, sendo que o primeiro é indicado para a via onde o veículo estará em movimento e o segundo para pontos de parada (DNIT, 2006).

-Pavimentos flexíveis: composto por camada de regularização, reforço do subleito, sub-base, base e revestimento. Tem como objetivo resistir e distribuir esforços obtidos devida carga aplicada por meio do tráfego de veículos, de forma aproximadamente equivalente em todas as camadas, devido sua elasticidade, os pavimentos flexíveis apresentam maior flexibilidade, e maior resistência a deformações (DNIT, 2006).

\section{TIPOS DE REVESTIMENTO}

Revestimento é a camada superior de um pavimento destinada a resistir aos esforços provenientes do tráfego de veículos, ou seja, a superfície do pavimento seja ele rígido, semirrígido, ou flexível, constituído de agregados e ligante asfáltico quando flexível, ou de concreto caso seja um pavimento rígido. $O$ tipo de revestimento a ser utilizado varia de acordo com a disponibilidade de matéria prima, exigências do local a ser pavimentado, e conforme a exigência de projeto. Entre os principais tipos de revestimentos temos o PC, PMF, MRAF, CBUQ e TS, além dos modificados por polímeros, e com adição de borracha moída de pneu inservível. 


\subsection{PAVIMENTOS DE CONCRETO (PC)}

Analisando os PC, de acordo com Pavimentos de concreto de Balbo (2009), podemos defini-los como pavimentos constituídos de placas de concretos, podendo haver presença de armadura longitudinal, e são classificados como pavimentos rígidos. Pode-se destacar entre os principais tipos:

Pavimento de Concreto Simples (PCS): Pavimento constituído de placas de concreto moldadas, não apresenta armadura longitudinal (BALBO, 2009).

Pavimento de Concreto Armado (PCA): É formado por sequências de placas de concreto armado, devido armadura utilizada apresentar função estrutural o pavimento exige menor utilização de Barras de Transferência (BT) e Barras de Ligação (BL) na construção do mesmo (BALBO, 2009).

Pavimento de Concreto com Armadura Contínua (PCAC): Caracteriza-se pela presença de armadura longitudinal contínua em toda sua estrutura, os PCAC possibilitam uma placa sem juntas. É importante ressaltar que a armadura contínua presente no PCAC não tem função estrutural (BALBO, 2009).

Pavimento de Concreto Protendido (PCPRO): Constituído de concreto convencional e cabos produzidos de arames de aço, porém mais densos e com menos fios do que os cabos de aço convencionais, ou seja, as chamadas cordoalhas protendidas, ou cabos de proteção (BALBO, 2009).

Pavimento de Concreto Pré-Moldado (PCPM): São constituídos de placas de concreto pré-moldadas que possuem armaduras com função de proporcionar resistência suficiente para que sejam capazes de suportar o seu peso próprio durante toda sua movimentação e transporte (BALBO, 2009).

Podemos então verificar que o revestimento de concreto é diferenciado pela presença de armaduras em sua composição, e suas funções estruturais. 


\subsection{PRÉ MISTURADOS A FRIO (PMF)}

O PMF é uma mistura composta por agregado graúdo, agregado miúdo, material de enchimento, e ligante asfáltico, produzido em temperatura ambiente, e em usina apropriada. Essa alternativa tem ganho espaço devido a sua boa trabalhabilidade em temperatura ambiente, e possibilidade de estocagem quando não será utilizado de imediato. Geralmente o PMF é indicado para aplicação em vias que apresentam baixo volume de tráfego, por não apresentar uma boa resistência a cargas quando comparado ao CBUQ (BERNUCCl et al., 2006).

\subsection{MICRORREVESTIMENTO ASFÁLTICO A FRIO (MRAF)}

Baseando-se em Manual de microrrevestimento asfáltico a frio - MRAF de Ceratti e Reis (2011), o MRAF pode ser definido como uma mistura asfáltica a frio constituída de agregados miúdos, material de enchimento, água, emulsão polimerizados e aditivos, sem poder estrutural, usada para correção em um pavimento quando o mesmo ainda apresenta patologias pequenas, como rachaduras, impossibilitando que essas patologias venham a se agravar e se tornar buracos no pavimento. O MRAF permite uma liberação rápida ao tráfego, devido sua aplicação ser simples e rápida, e tem custo inferior quando comparado com um recapeamento convencional, além de preservar a capacidade estrutural do pavimento, se aplicado no tempo certo.

\subsection{CONCRETO BETUMINOSO USINADO A QUENTE (CBUQ)}

O CBUQ é o material para a construção de revestimento de pavimentos mais tradicional e comum no Brasil, portanto até então o mais utilizado, composto por múltiplas camadas, porém tendo o revestimento como a camada responsável por receber e transmitir as cargas dos veículos para as camadas subjacentes. Trata-se de uma mistura asfáltica produzida à quente em uma usina misturadora específica, de grande, médio, ou pequeno porte, mistura essa composta de agregados minerais em geral bem graduados, material de enchimento (fíler) podendo ser cal ou cimento, e ligante betuminoso, e que deve ser lançada e compactada a quente na pista a ser pavimentada (BALBO, 2007). 
A execução da pavimentação de um determinado local utilizando CBUQ é realizada a partir da preparação do solo, pintura de ligação, e espalhamento do material na pista com vibroacabadoras, em seguida deve-se iniciar o processo de rolagem para compactação do mesmo, sendo iniciada pelos bordos longitudinalmente, continuando em direção ao eixo da pista, quando em curvas horizontais a compactação deverá iniciar sempre do ponto mais alto para o ponto mais baixo de acordo com a superelevação da curva, a temperatura ideal do ligante varia entre $107^{\circ} \mathrm{C}$ e $177^{\circ} \mathrm{C}$ (BALBO, 2007). O processo de usinagem asfáltica do CBUQ é realizado conforme apresentado na figura 1 :

Figura 1 - Processo de usinagem do CBUQ

\section{ETAPAS DO PROCESSO DE USINAGEM ASFÁLTICA.}
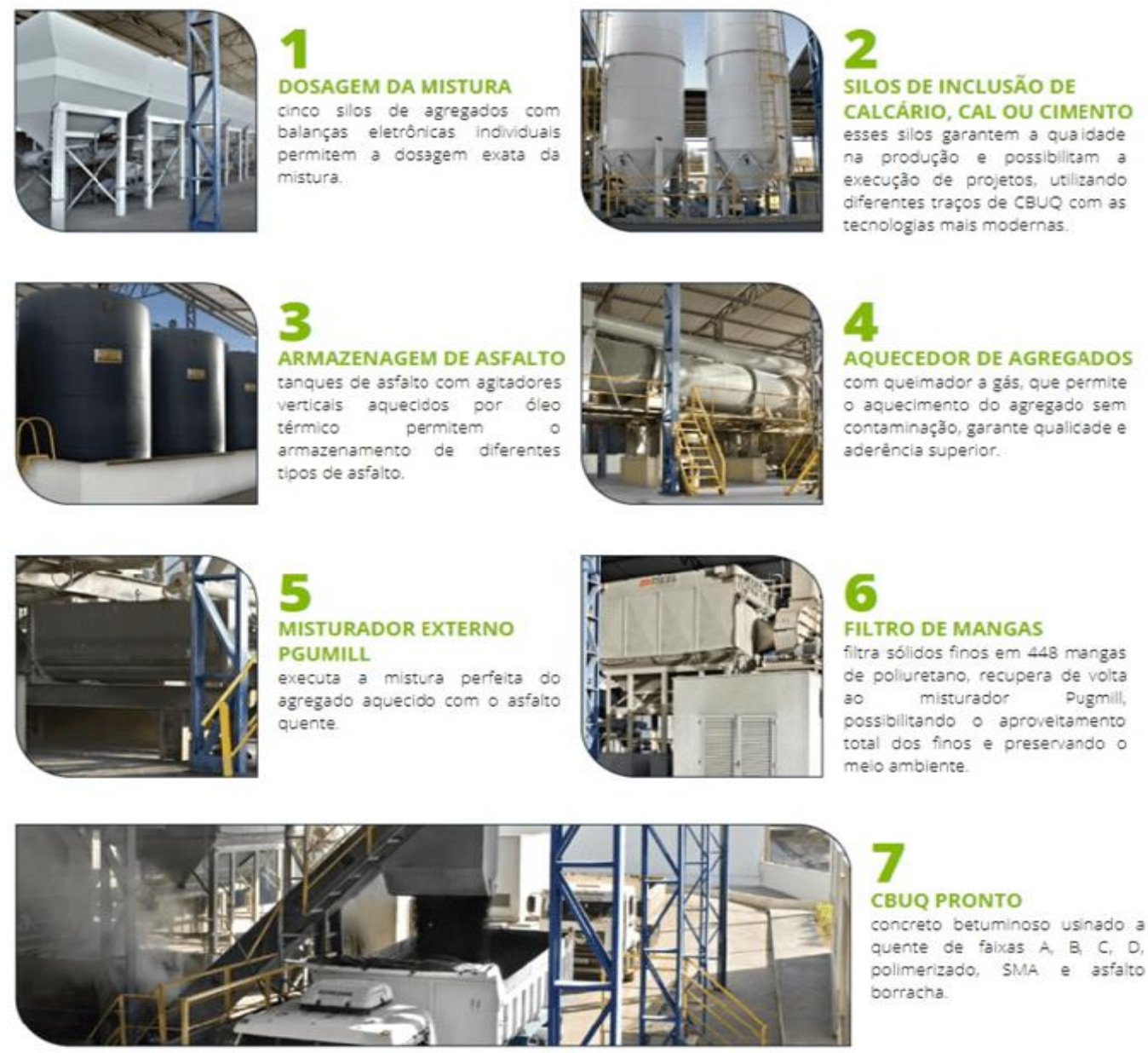

Fonte: Ribpav. Etapas do processo de usinagem 


\subsection{TRATAMENTO SUPERFICIAL (TS)}

Segundo Pavimentação asfáltica de Pinto e Pinto (2015), "TS são capas delgadas de rolamento, em que o agregado e o material betuminoso são espalhados sobre a superfície a ser revestida".

Podemos definir TS como a camada de desgaste de um pavimento flexível, podendo constituir a camada de revestimento de um novo pavimento, ou recapeamento de revestimentos antigos, proporciona um pavimento com uma camada de rolamento de pequena espessura, porém de alta resistência. Os TS são classificados como simples, duplo, e triplo, conforme o número de aplicações de agregado e ligante (PINTO; PINTO, 2015).

- Tratamento Superficial Simples (TSS), ocorre apenas uma aplicação do ligante, sendo esta seguida de uma cobertura de agregado, geralmente é utilizado em pavimentação que tenha baixo custo (PINTO; PINTO, 2015).

- Tratamento Superficial Duplo (TSD), é realizado duas aplicações de ligante, sendo cada uma delas seguida de uma cobertura de agregado, utilizados normalmente em rodovias as quais possua baixo volume de tráfego (PINTO; PINTO, 2015).

- Tratamento Superficial Triplo (TST), é realizado três aplicações de ligante, sendo cada uma delas seguida de uma cobertura de agregado, utilizados em vias recém implantadas que apresentam médio volume de tráfego (PINTO; PINTO, 2015).

Conforme o exposto, temos alguns dos tipos de revestimento, sendo estes os mais usuais, mesmo sabendo que a borracha moída pode ser adicionada em qualquer dos revestimentos flexíveis, o que melhor possibilita a modificação do CAP com acréscimo do polímero é o tipo de revestimento CBUQ.

\section{POLÍMEROS}

Os polímeros são definidos basicamente como macromoléculas obtidas pela união sequenciada de monômeros, sendo os principais tipos de polímeros, os termorrígidos, 
termoplásticos, elastômeros, e elastômeros termoplásticos. Na pavimentação, os polímeros a serem aplicados devem apresentar propriedades químicas compatíveis com o asfalto a ser modificado.

- Termorrígidos: São aqueles que endurecem por ação do calor de forma irreversível, e quando reaquecidos não amolecem novamente, por aquecimento assumem estrutura tridimensional resistente a qualquer mudança de temperatura; exemplos: resina epóxi, poliuretano, poliéster (PINTO; PINTO, 2015).

- Termoplásticos: São aqueles que amolecem quando aquecidos, e endurecem quando resfriados, possibilitando seu tratamento e moldagem repetidas vezes, consistem em cadeias lineares podendo também ser ramificadas, são incorporados ao asfalto a alta temperatura, apresentam boa resistência ao envelhecimento; exemplos: polietileno, polipropileno, PVC (PINTO; PINTO, 2015).

- Elastômeros: Apresentam propriedades elásticas, quando não vulcanizados apresentam comportamento plástico, os elastômeros suportam grande deformação antes de sua ruptura; exemplo: Estireno Butadieno (SBR), borracha vulcanizada. Sendo o SBR de fácil incorporação ao CAP e não requer agitador de alto cisalhamento (PINTO; PINTO, 2015).

- Elastômeros termoplásticos: São aqueles que, ao serem aquecidos apresentam comportamento termoplástico, e resfriados apresentam propriedades elásticas; exemplo: Estireno Butadieno Estireno (SBS), sola de sapato, e Etileno Acetato de Vinila (EVA) (PINTO; PINTO, 2015).

Diante a apresentação dos tipos de polímeros existentes, a borracha sintética de pneu utilizada para modificação do CAP no pavimento de asfalto borracha, é classificada como polímero elastômero, devido sua facilidade de incorporação no revestimento.

\section{ASFALTO MODIFICADO}

De acordo com Bernucci et al. (2006), 
Nem todos os polímeros são passíveis de serem adicionados ao CAP e nem todo CAP quando modificado por polímero apresenta estabilidade e estocagem. Os asfaltos que melhor se compatibilizam com polímeros são aqueles que apresentam uma certa aromaticidade. A quantidade de polímero que se deve ser adicionada ao ligante é variável e depende das propriedades finais desejadas. (BERNUCCl et al., 2006, p.63).

Entende-se que asfalto modificado é todo aquele que tem as suas características melhoradas através da aplicação de aditivos químicos ou elastômeros. Os asfaltos modificados com polímeros visam aumentar a resistência às deformações, e melhorar o desempenho do pavimento quanto à fadiga.

\subsection{BORRACHA DE PNEU NA PAVIMENTAÇÃO}

A utilização de pneus no dia a dia da sociedade tem finalidades fundamentais e insubstituíveis, seja para veículos de transporte de passageiros, ou veículos que transportam cargas. No entanto, com o decorrer do tempo de utilização os pneus vêm gerando diversos problemas ambientais, devido seu acúmulo e descarte de forma incorreta dos mesmos. Embora haja pontos de coletas apropriados para os pneus inservíveis, e existência de norma regulamentada, que tem finalidade de dar uma destinação final a este material após sua vida útil. Sabe-se que grande parte dos pneus inservíveis é descartada de maneira incorreta, o que acarreta possíveis problemas ao meio ambiente, como a poluição de rios e lagos, e também a proliferação de doenças.

De acordo com o Conselho Nacional do Meio Ambiente (CONOMA), foi estabelecido norma com propósito de dar destinação final aos pneus pós sua vida útil, e assim proteger a natureza de possíveis danos quando o descarte é realizado de forma inadequada, conforme o item A e B:

A) para cada quatro pneus novos fabricados no País ou pneus novos importados, inclusive aqueles que acompanham os veículos importados, as empresas fabricantes e as importadoras deverão dar destinação final a cinco pneus inservíveis; 
B) para cada três pneus reformados importados, de qualquer tipo, as empresas importadoras deverão dar destinação final a quatro pneus inservíveis. (CONAMA 258-99).

A pavimentação utilizando revestimento com o CAP modificado por polímeros pode vir a ser uma solução para o descarte inadequado de pneus inservíveis, podendo ser utilizados como um elastômero introduzido ao CAP, com função de agir como um modificador, após passar por um processo de reciclagem, onde é separado para utilização apenas a borracha sintética do pneu. A utilização da borracha moída de pneu como modificador do CAP, proporciona ao pavimento vantagens como maior vida útil, melhor adesividade do ligante aos agregados, maior resistência a deformações, e maior flexibilidade.

\subsection{PROCESSO DE RECICLAGEM DE PNEUS INSERVÍVEIS PARA USO EM PAVIMENTAÇÃO}

O processo de reciclagem da borracha para utilização na pavimentação é realizado a partir da separação da borracha sintética do pneu inservível, sendo retirado todo o aço presente no pneu, logo após essa separação, a borracha sintética passa por um processo de moagem, depois é triturada, a borracha já moída e triturada é aquecida em um tambor/secador, e é armazenada em silos, em seguida é misturada ao betume, e adicionado agregado (areia e brita), assim resulta na Borracha Misturada ao Betume (BMB), essa massa é colocada em caminhões basculantes e então levada para a obra.

Logo a seguir, temos um organograma apresentando a sequência em que é realizado esse processo de reciclagem da borracha de pneus inservíveis, para utilização na pavimentação asfáltica, conforme a figura 2: 
Figura 2 - Organograma representativo do processo de reciclagem da borracha para pavimentação.

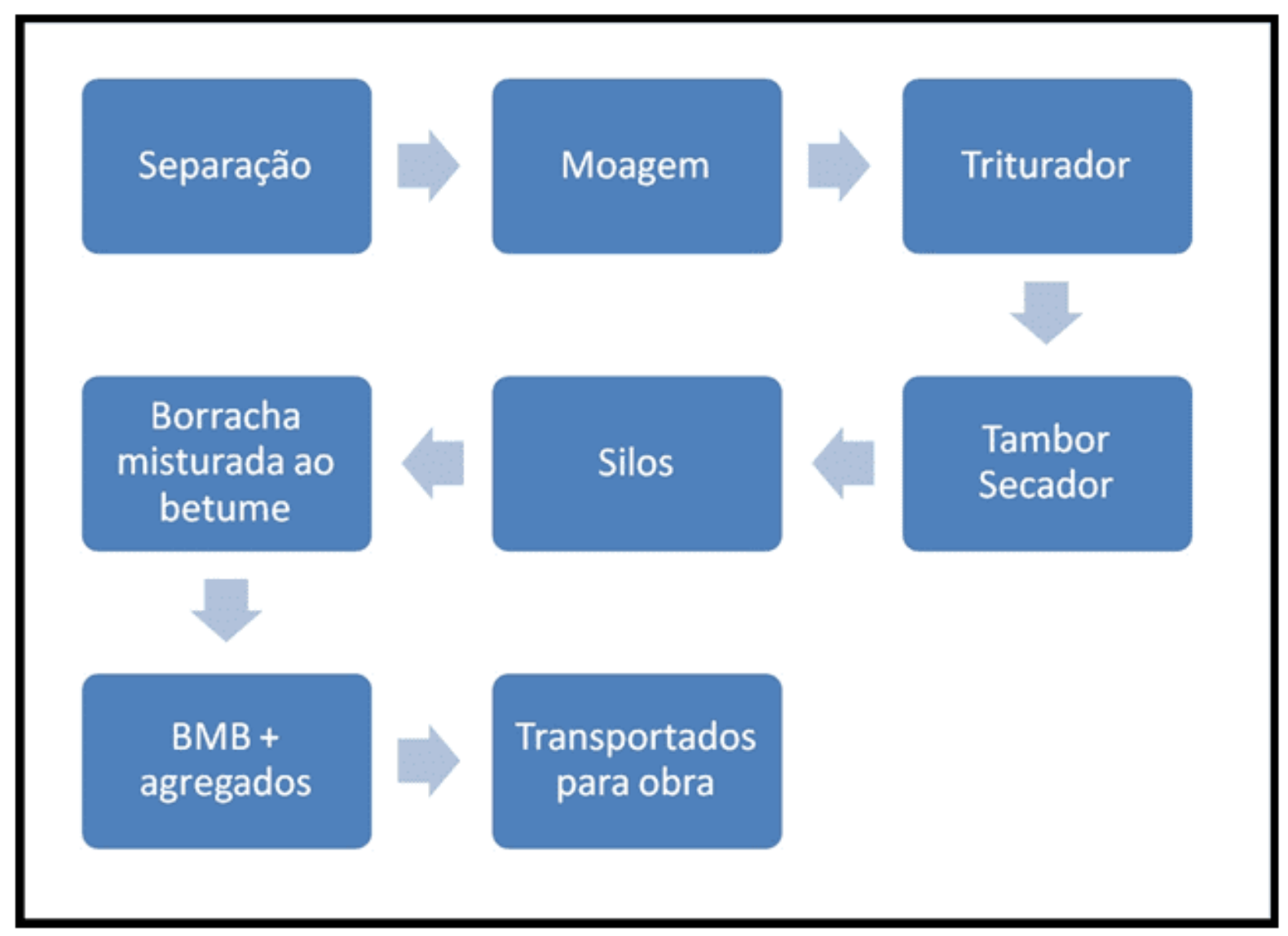

Fonte: Própria autora.

\section{CBUQ COM ADIÇÃO DE BORRACHA}

O Asfalto borracha, também conhecido como asfalto ecológico, é produzido nos Estados Unidos desde a década de 40, porém no Brasil essa inovação chegou a cerca de 10 anos, no início muitas empresas tentaram adotar a produção de asfalto borracha, porém devido o alto custo, e também por ser um material de difícil trabalhabilidade, nem todas conseguiram prosseguir trabalhando com esse tipo de revestimento, um dos problemas para fabricação do asfalto borracha é que no caso o misturador venha a ficar parado, a borracha pode vir a decantar facilmente, correndo o risco de até mesmo perder o equipamento utilizado (tambor misturador), o grupo Greca Asfaltos tem se destacado por ser a única empresa a continuar acreditando e 
investindo em sua utilização, a empresa conseguiu continuar a utilizar o asfalto borracha através de pesquisas que trouxeram melhoramento ao ligante asfáltico utilizado em questão.

A adição do pó de borracha ao revestimento apresenta uma melhora de até 30\% ao pavimento, proporcionando maior vida útil, maior resistência ao calor, maior resistência a deformações, maior flexibilidade, melhor adesividade do ligante aos agregados, maior resistência ao desgaste ocasionado pelo tráfego da pista, maior resistência ao envelhecimento, melhor aderência entre o pneu e o pavimento, diminuição do efeito spray em períodos de chuvas, e ajuda a evitar a formação de espelho d'água na pista, além de reduzir o ruído do tráfego.

O asfalto borracha é obtido a partir do acréscimo da borracha moída de pneu à massa asfáltica, podendo ser realizado por dois processos sendo eles a seco, ou úmido. No processo a seco, a borracha é introduzida nas usinas de asfalto durante o preparo da mistura asfáltica, a borracha é incorporada como substituição de parte do agregado. No processo úmido, a borracha é previamente misturada ao ligante, e incorporada ao CAP como um ligante modificador. A seguir exemplos no Brasil de pavimentos executados com asfalto borracha, conforme apresentado na figura 3 , figura 4, figura 5 , figura 6 , e figura 7 : 
Figura 3 - Rodovia Anhanguera e Bandeirantes

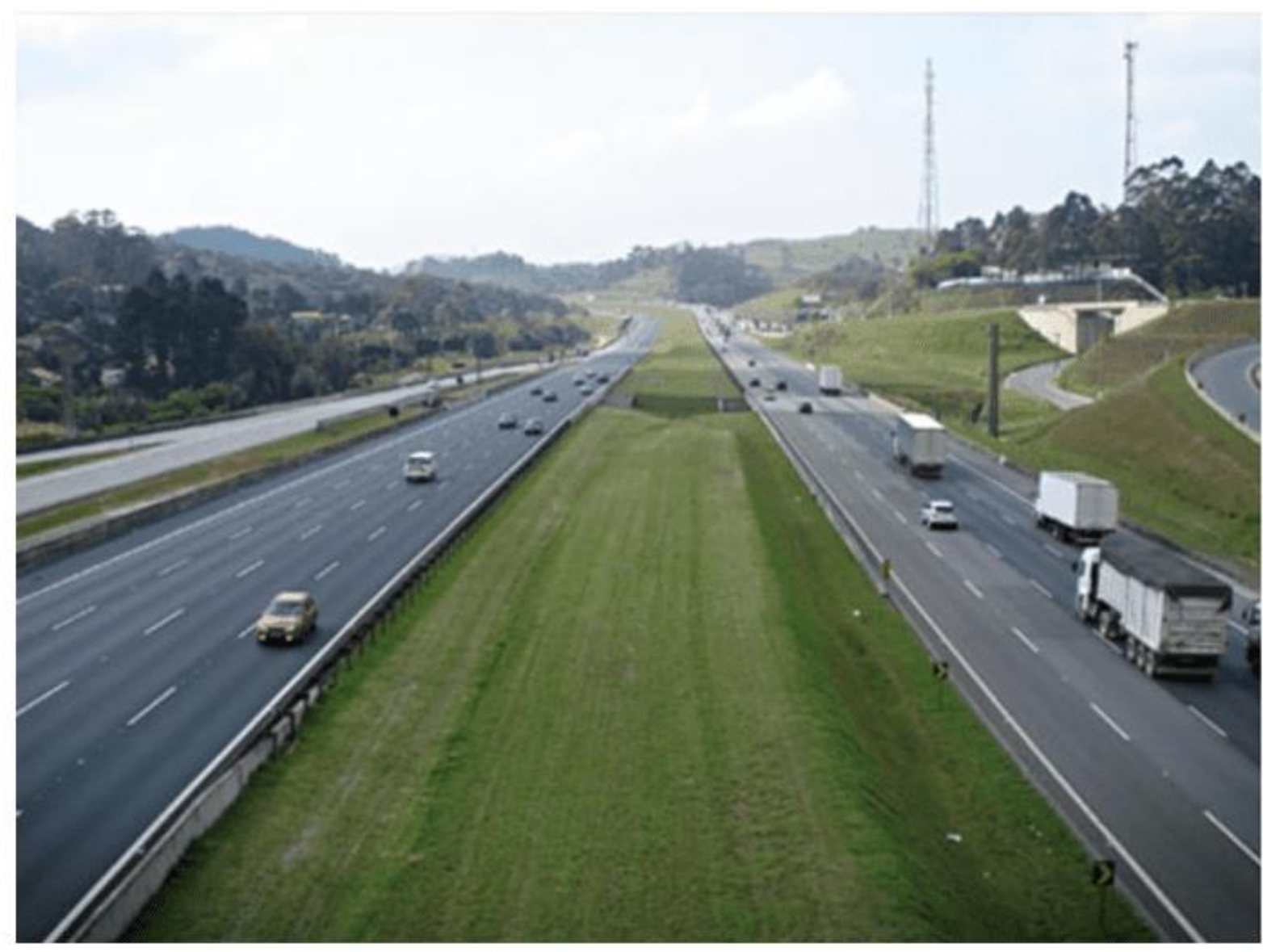

Fonte: Greca asfaltos. Ecoflex: 10 milhões de pneus retirados da natureza. 


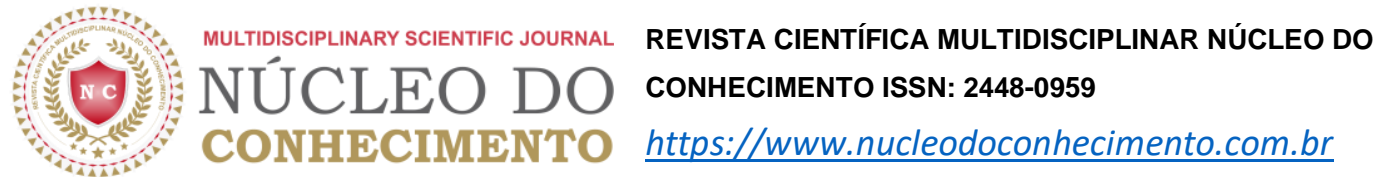

Figura 4 - Sistema Anchieta e Imigrantes

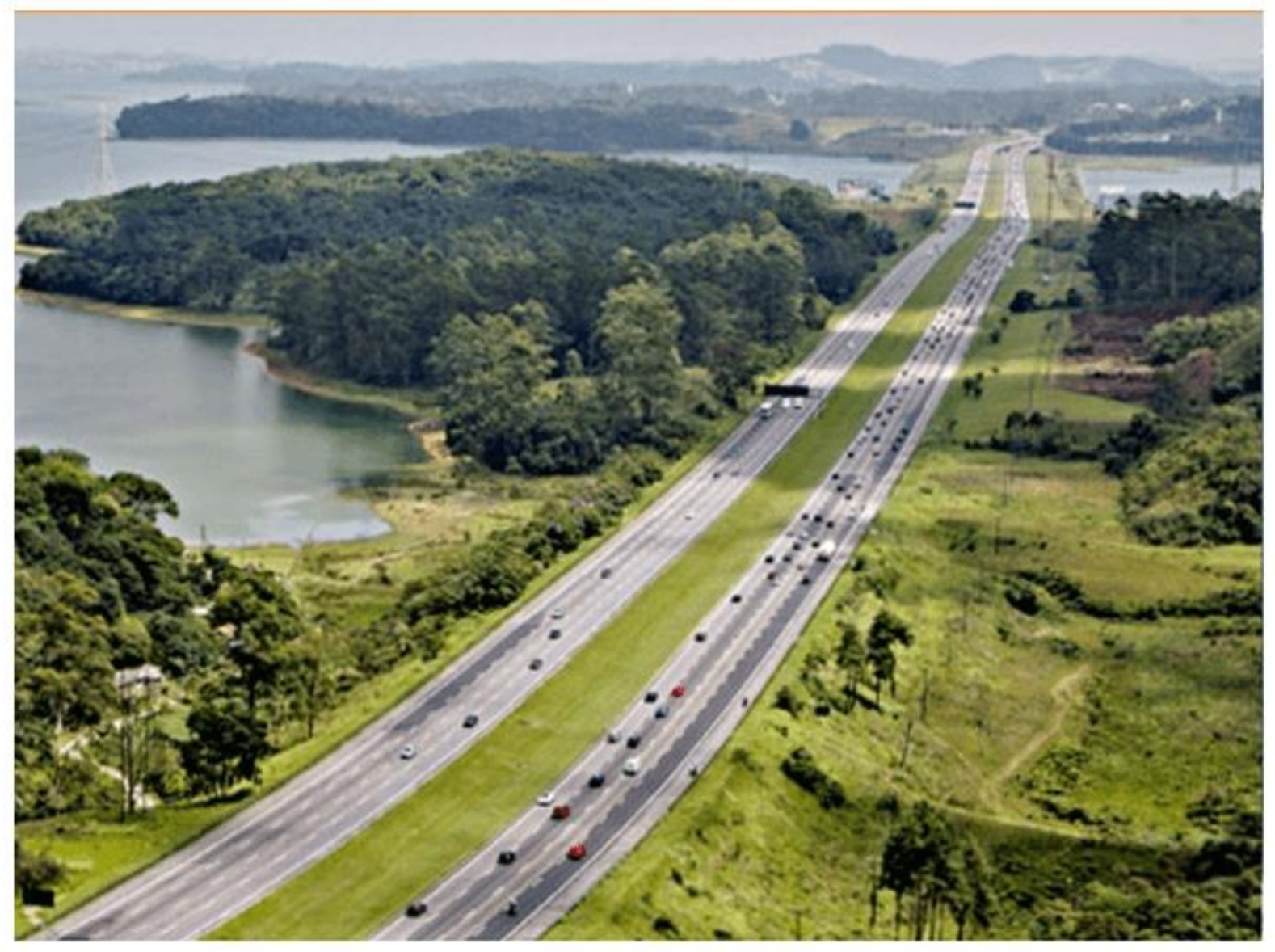

Fonte: Greca asfaltos. Ecoflex: 10 milhões de pneus retirados da natureza. 
Figura 5 - BR-050 entre Minas e Goiás

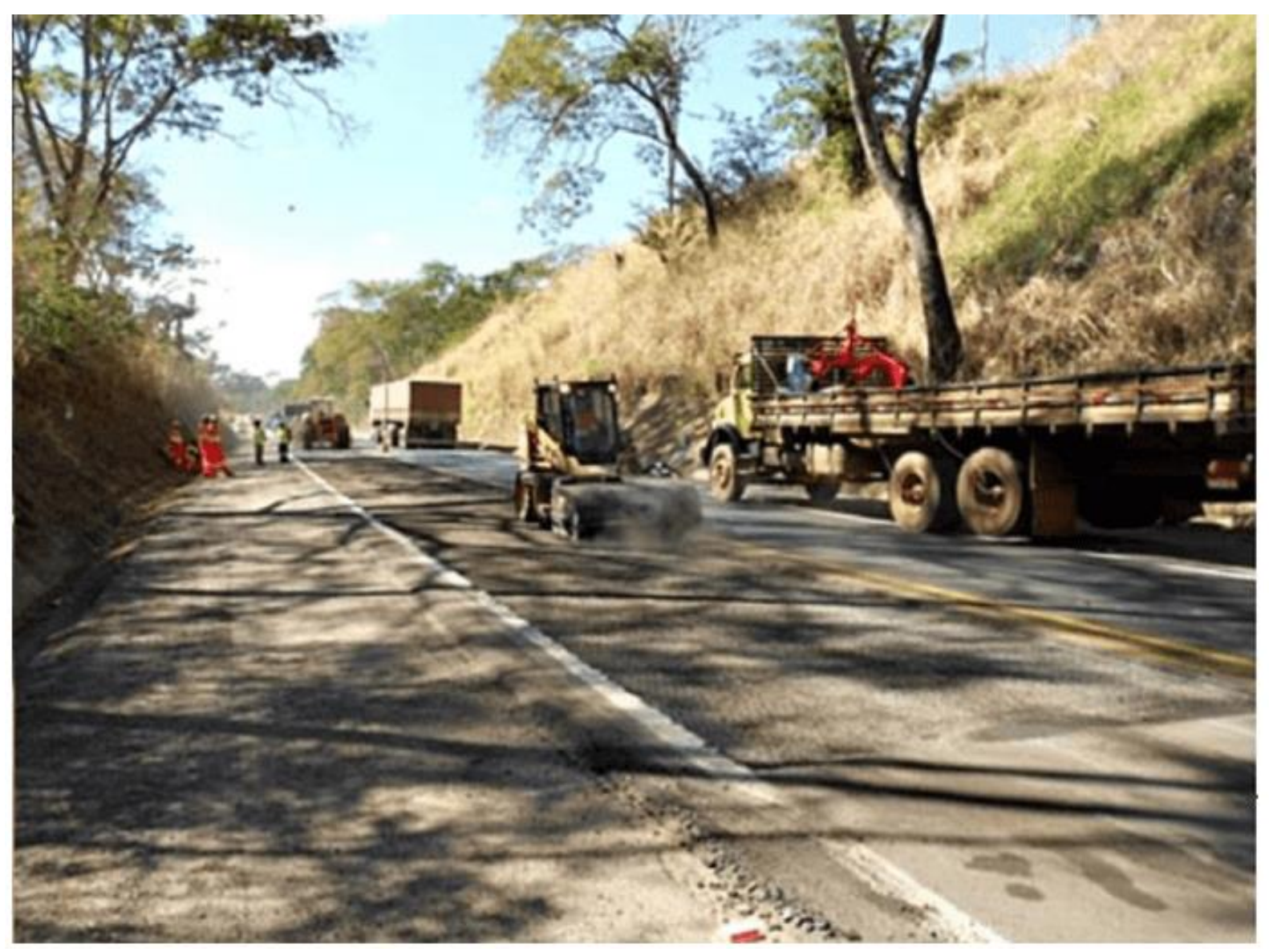

Fonte: Greca asfaltos. Ecoflex: 10 milhões de pneus retirados da natureza. 


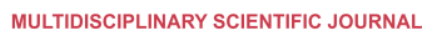

Figura 6 - AV Beira mar norte em Florianópolis-SC

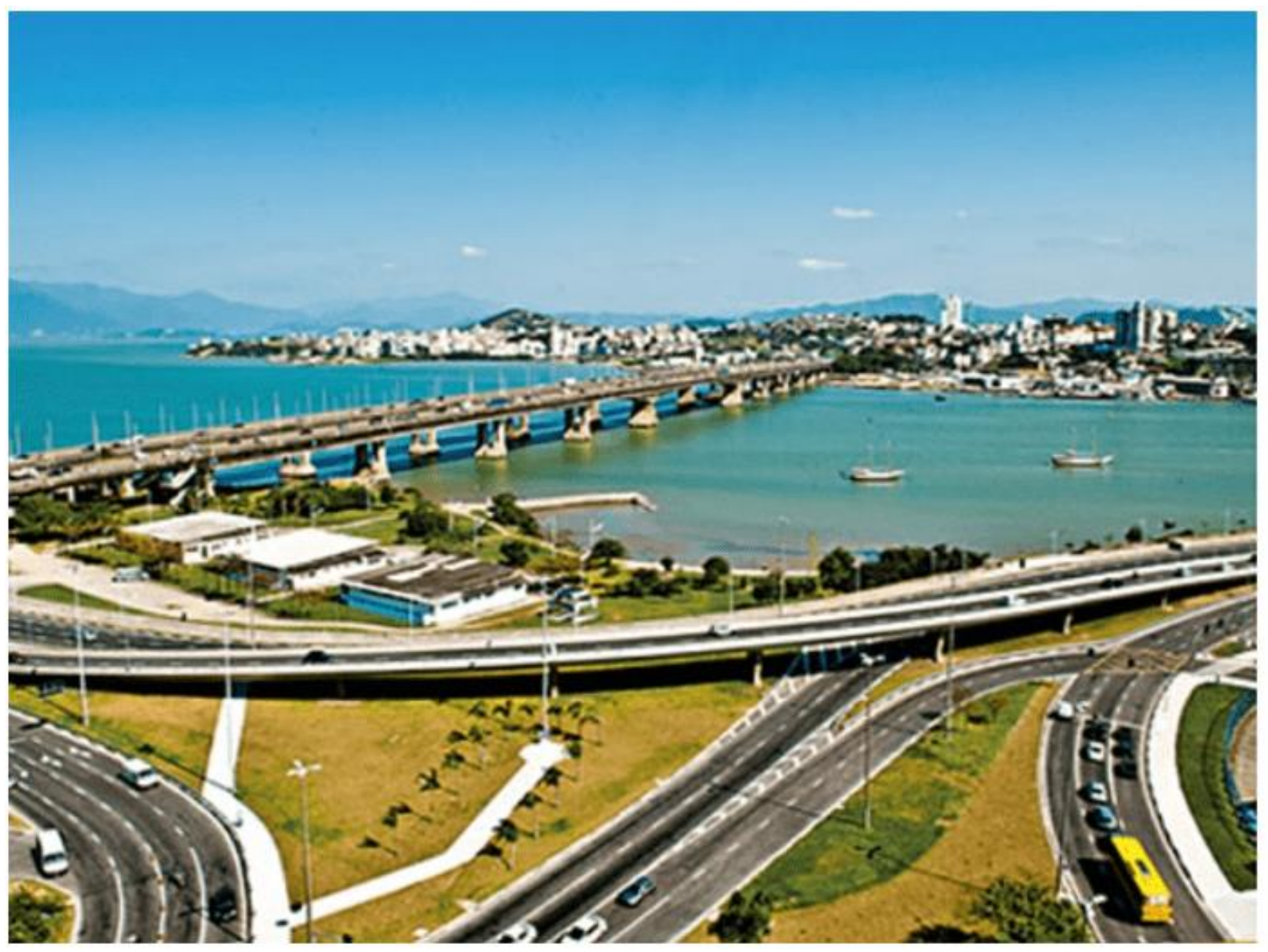

Fonte: Greca asfaltos. Ecoflex: 10 milhões de pneus retirados da natureza. 
Figura 7 - Vias internas da usina de Itaipu-PR

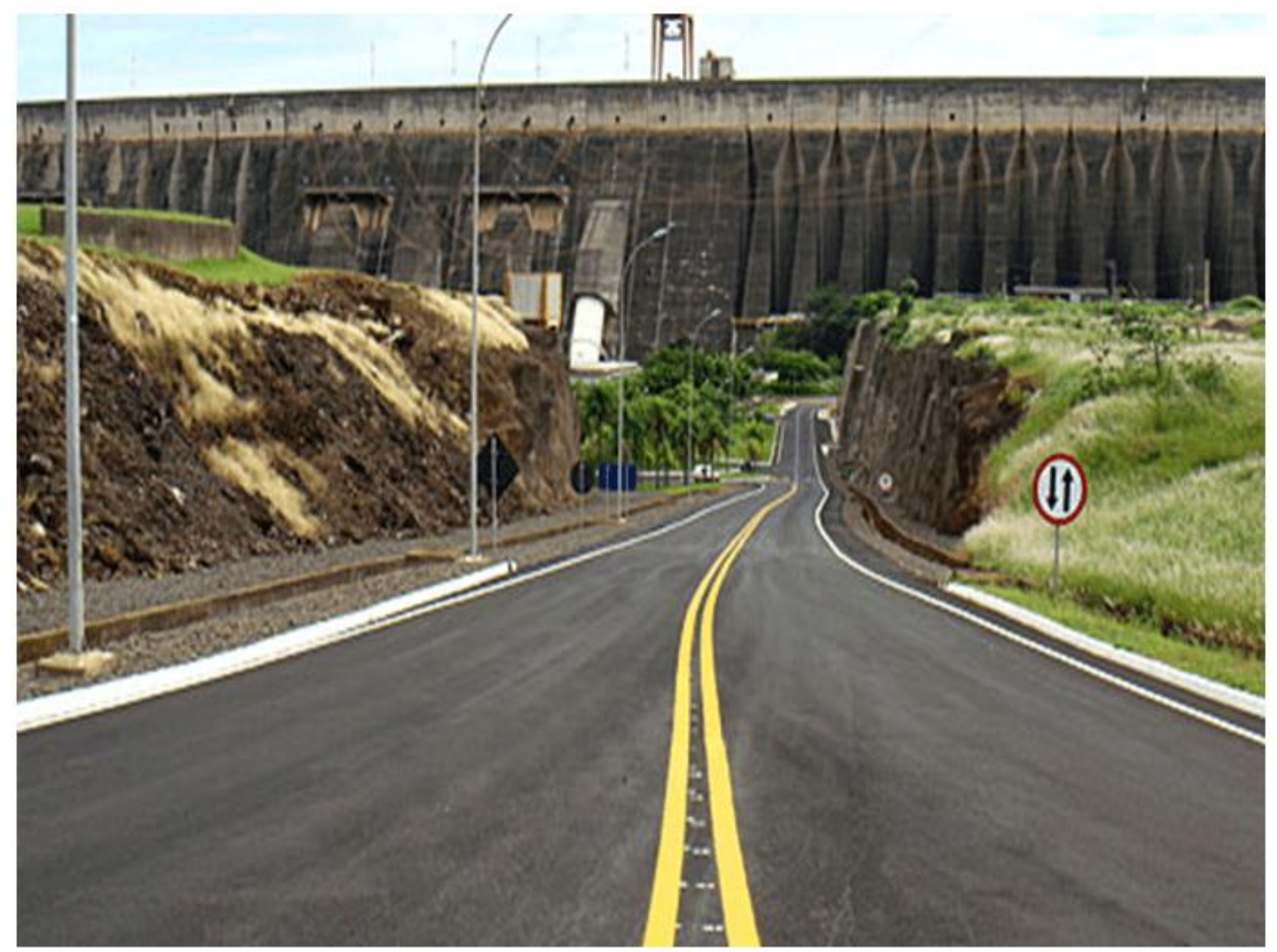

Fonte: Greca asfaltos. Ecoflex: 10 milhões de pneus retirados da natureza.

\section{CONSIDERAÇÕES FINAIS}

O estudo bibliográfico apresentou a praticidade, e efeitos positivos ocasionados no comportamento de revestimentos asfálticos, quando introduzido borracha moída de pneus inservíveis ao CAP, com a finalidade de agir como modificador do ligante, mostrando assim uma melhor condição de pavimento que poderíamos ter com o uso do asfalto borracha, tendo em vista as vantagens proporcionadas ao pavimento em que é utilizado este tipo de revestimento modificado. Um dos pontos importantes é que o pavimento de asfalto borracha tem vida útil superior ao pavimento convencional, o que compensaria seu maior custo inicial devido a reciclagem da borracha. 
No entanto, é possível observar a falta de investimento e incentivo político em empresas do ramo, para a utilização deste material reciclado, sendo que este pode ser utilizado na pavimentação, proporcionando vantagens ao pavimento em que é usado tais resíduos, no caso deste estudo, a borracha de pneu inservível, o uso de resíduos sólidos na pavimentação proporciona também a redução dos impactos ambientais ocasionados através do seu descarte incorreto no meio ambiente. Embora existam normas regulamentadoras que visão obrigar os fabricantes e importadores de pneus, a dar destinação final adequada aos pneus pós sua vida útil, o índice de reaproveitamento de pneus inutilizáveis no Brasil é baixo quando comparado com a quantidade de pneus fabricados.

A incorporação da borracha moída de pneus inutilizáveis ao ligante asfáltico mostrase muito eficaz, em aspectos comportamentais do pavimento, proporcionando resultados extremamente satisfatórios em vias que são pavimentadas com revestimento de asfalto borracha. Diante das informações apresentadas no decorrer deste estudo bibliográfico, considera-se totalmente viável o uso do pavimento de asfalto borracha, o que com maior incentivo político, com certeza será a alternativa de revestimento mais utilizada, proporcionando à população vias com maior qualidade, conforto e segurança.

\section{REFERÊNCIAS}

BALBO, J. T. Pavimentação asfáltica materiais, projeto e restauração. Oficina de textos: São Paulo. 2007.

BALBO, J. T. Pavimentos de concreto. Oficina de textos: São Paulo. 2009.

BERNUCCI, L.B; MOTTA, L. M. G; CERATTI, J. A. P; SOARES, J.B. Pavimentação asfáltica formação básica para engenheiros. Rio de Janeiro. 2006.

CERATTI, J, A, P; REIS, R, M. M. Manual de microrrevestimento asfáltico a frio MRAF. Oficina de textos: Rio de Janeiro. 2011. 
CONAMA. Conselho Nacional do Meio Ambiente. № 258. Gestão resíduos e produtos perigosos. 1999.

DNIT. Departamento Nacional de Infraestrutura de Transporte. Manual de Pavimentação. Disponível em:

<http://www1.dnit.gov.br/arquivos_internet/ipr/ipr_new/manuais/Manual\%20de\%20P avimenta\%E7\%E3o_05.12.06.pdf>. Acesso em: 26 mai. 2019.

GRECA ASFÁLTOS. Ecoflex: 10 milhões de pneus retirados da natureza. Disponível em: <http://www.asfaltoborracha.com.br>. Acesso em: 27 mai. 2019.

PINTO, S; PINTO, I. E. Pavimentação asfáltica conceitos fundamentais sobre materiais e revestimentos asfálticos. LTC: Rio de Janeiro. 2015.

Enviado: Julho, 2020.

Aprovado: Setembro, 2020. 